\title{
Saúde mental e perspectivas terapêuticas no cenário da COVID-19
}

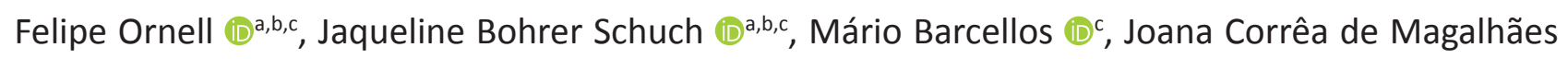
Narvaez $\mathbb{D}^{c, d}$

a Universidade Federal do Rio Grande do Sul, Faculdade de Medicina, Programa de Pós-Graduação em Psiquiatria e Ciências do Comportamento, Porto Alegre - RS, Brasil. ${ }^{b}$ Centro de Pesquisa em Álcool e Drogas, Hospital de Clínicas de Porto Alegre, Universidade Federal do Rio Grande do Sul, Porto Alegre - RS, Brasil. ' Centro de Estudos Luís Guedes, Hospital de Clínicas de Porto Alegre / Universidade Federal do Rio Grande do Sul, Porto Alegre-RS, Brasil. ${ }^{d}$ Universidade Federal de Ciências da Saúde de Porto Alegre, Curso de Psicologia, Porto Alegre - RS, Brasil.

DOI 10.5935/2318-0404.20210019

O incômodo é um dos combustíveis que move a máquina chamada ciência. Os avanços mais substanciais na produção científica e tecnológica ao longo da história não ocorreram aleatoriamente, mas a partir de grandes crises. Afinal, como dizia Rubem Alves: "ostra feliz não faz pérola". O óbvio, por vezes esquecido, é que estratégias são desenvolvidas a partir do reconhecimento de problemas que, para que se mitigue, é preciso em primeira instância admitir.

Os problemas relacionados à saúde mental, potencializados pela pandemia da COVID-19, já são reconhecidos há algum tempo pelas principais entidades internacionais de saúde. A efetivação de políticas estratégicas em saúde mental, no entanto, esbarra em dificuldades também de longa data, como o preconceito e a negação. Frequentemente, esses elementos fazem com que o problema, bem estabelecido a nível macro, não seja plenamente admitido por formuladores de políticas locais e principalmente por pessoas que vivenciam sofrimento psíquico. Apesar dos avanços notórios identificados nas últimas décadas, o investimento em processos de prevenção, promoção e recuperação da saúde mental ainda é expressivamente inferior a outras áreas da saúde humana, o que torna lícito concluir que essa área é dona de um título nada louvável: o de campeã em negligência.

A crise gerada pela COVID-19 tem efeitos intensos e de alcance variado, entretanto fortaleceu a discussão da saúde mental como parte inerente da própria saúde humana. Paralelamente à pandemia biológica, desenvolveu-se uma pandemia de medo, em que grande parte da população passou a apresentar - de forma transitória ou persistente - algum sintoma de saúde mental ou comportamental. Este cenário pode ser explicado 
pela apreensão diante do vírus e de suas consequências, como o desconhecimento dos mecanismos virais e de contaminação, além do impacto econômico e social das medidas restritivas, bem como em decorrência de processos de isolamento, doença e luto.

Talvez seja a primeira vez que o sofrimento é universalmente legitimado, apesar dos interesses políticos e econômicos de uma máquina que não pode parar e que usa como combustível a energia de cada um de nós. $O$ contexto de vulnerabilidade global valida as ações dos profissionais da área psicossocial, mas também destaca antigos desafios, sobretudo relacionados à efetivação da universalidade, integralidade e equidade no acesso aos cuidados em saúde mental.

Tragédias e epidemias recentes, porém geograficamente limitadas, nos mostraram que as consequências na saúde mental da população podem ser mais duradouras do que a própria crise. Precisamos, portanto, estar preparados para desenvolver estratégias de prevenção, rastreamento e tratamento. As novas tecnologias passaram a facilitar o acesso à assistência em saúde mental, mas também impuseram novos elementos no setting terapêutico. Pautas clássicas e emergentes se aproximam e nos confrontam com uma demanda crônica: encontrar a melhor estratégia terapêutica para aliviar o sofrimento e melhorar a qualidade de vida das pessoas. Isso é especialmente complexo em um país continental e com grandes disparidades, como o Brasil, onde o distanciamento físico acentuou o distanciamento socioeconômico. De um lado aqueles que puderam escolher se preservar, de outro, aqueles que nem se expondo conseguiram o suprimento de necessidades básicas. Marcadores sociais passíveis de alavancar os índices de adoecimento mental populacional e de incremento de sintomas de externalização comunitários.

Esta primeira edição da Revista Brasileira de Psicoterapia de 2021 reúne produções que discorrem sobre as implicações da COVID-19 na saúde mental e nas psicoterapias, compartilhando experiências e perspectivas de diferentes profissionais e pesquisadores que atuam em diferentes contextos. Em tempos em que a ciência é atacada, torna-se ainda mais premente a produção e difusão de conhecimento baseado em evidências - o que tem sido buscado incessantemente pela equipe editorial da Revista.

Editores da Revista Brasileira de Psicoterapia Centro de Estudos Luís Guedes 